\title{
Tribological response of waste tire rubber as micro-fillers in automotive brake lining materials
}

\author{
Anand PAI ${ }^{1, *}$, Sayikumar SUBRAMANIAN ${ }^{1,2}$, Tribhuvan SOOD ${ }^{1}$ \\ ${ }^{1}$ Department of Aeronautical and Automobile Engineering, Manipal Institute of Technology, Manipal Academy of Higher Education Manipal, \\ Karnataka 576104l, India \\ ${ }^{2}$ Cranfield University, Cranfield, Milton Keynes, Bedfordshire MK43 0AL, UK \\ Received: 07 September 2018 / Revised: 01 January 2019 / Accepted: 17 December 2019 \\ (C) The author(s) 2019.
}

\begin{abstract}
Elastomeric materials show promise as potential micro-fillers in brake linings. They can provide vibration damping and acoustic advantages in intermittent and abrupt impact applications such as braking. The elastomeric material can be salvaged from non-biodegradable automotive tires, thereby providing an opportunity to reuse materials that will otherwise be discarded in landfills. Both tribological and thermomechanical performances of the waste tire rubber were assessed to determine their potential for use as micro-fillers in the brake linings of commercial vehicles with a gross weight less than 16 tons. Accordingly, the brake lining materials were fabricated with fine waste tire rubber particulates (WTRPs) as the micro-fillers, phenolic-R resin as the binder, graphite as the dry lubricant, laterite as the co-filler, and coconut coir for natural fiber reinforcement. The effects of increasing the WTRP weight fraction on the brake response of the linings were analyzed, and the different compositions were benchmarked against a commercial brake lining. Mechanical characterization comprising compressive strength, hardness, density, and porosity studies were carried out. Frictional and wear characteristics of the linings were analyzed using a rotary tribometer with simultaneous thermal monitoring. The manufactured lining with $15 \mathrm{wt} \%$ WTRPs exhibited a mean friction coefficient of $\sim 0.38$, a specific volumetric loss rate of 1,662 $\mu \mathrm{m}^{3} /(\mathrm{N} \cdot \mathrm{m})$, and improved thermal response. Using optical microscopy and scanning electron microscopy (SEM) with energy dispersive spectroscopy (EDS), wear surface morphology studies compared the relative development of primary and secondary plateaus and revealed the redistribution of wear debris, leading to the stability of the coefficient of friction.
\end{abstract}

Keywords: automotive; brakes; elastomers; graphite; energy dispersive spectroscopy (EDS); scanning electron microscopy (SEM); wear mechanisms

\section{Introduction}

Braking in automobiles is the reverse process of acceleration. The latter involves the conversion of chemical energy of fuel into heat and kinetic energies, whereas in the former, the kinetic energy is transformed into heat energy. On applying the brakes, the brake torque at the brake discs or drums generates a negative tractive force at the wheels. Brake linings or shoes are an integral part of the friction pair used in conventional automotive foundation brake systems. The brake linings are pressed against the rotating component of the friction pair (i.e., the brake disc or drum) while braking. The coefficient of friction at the contact interface is vital to the transmittance of the brake torque and to the eventual deceleration. Friction, in turn, leads to wear on the friction-pair components, and the brake linings tend to be more prone to wear than the counter-rotating discs or drums. However, the specific wear rate of the brake linings must lie within

* Corresponding author: Anand PAI, E-mail: anand_pioneer@yahoo.com 


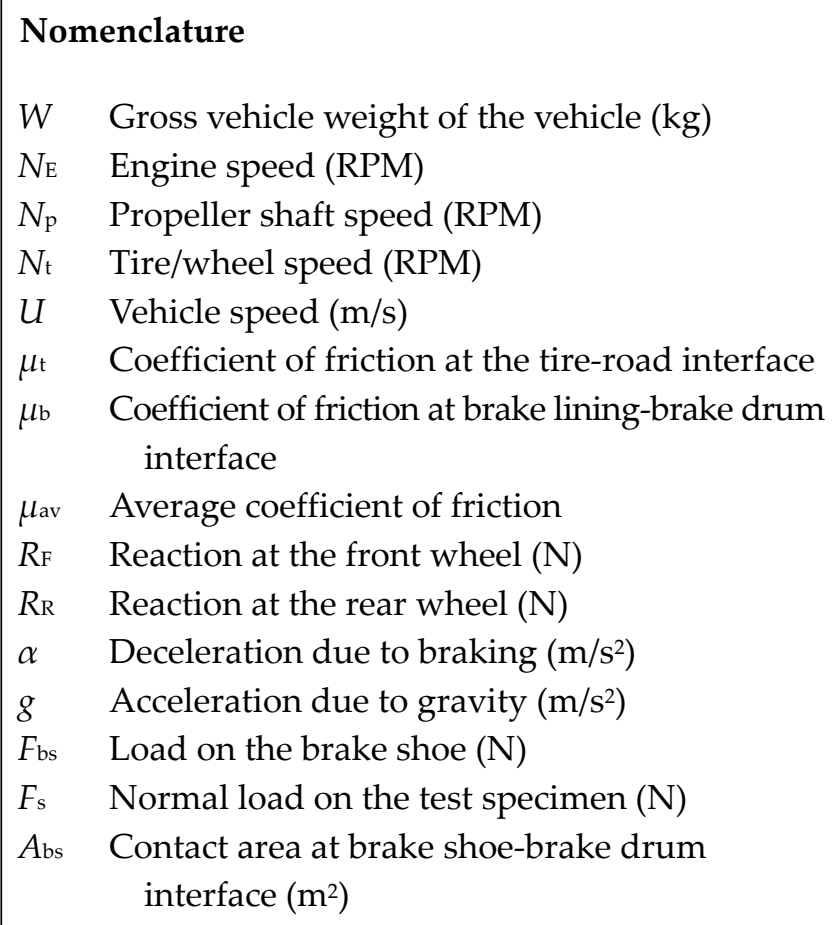

acceptable limits to ensure maximum automobile uptime. Wear of the brake lining material also helps in ensuring uniform distribution of contact pressure because the wear evens out the peaks and ridges on the surface. Because the brakes must perform instantaneous deceleration, there is significant heat production at the interface of the brake linings and the counter disc/drums [1]. This heat must be dissipated to prevent excessive temperature rise that can adversely affect the material properties of the brake lining and the discs/ drums. Heat dissipation is considerably influenced by the thermophysical material properties of the discs/ drums such as the thermal conductivity, heat capacity, and thermal diffusivity. Nevertheless, the brake lining materials must retain their structural integrity, strength, and hardness while offering a stable coefficient of friction over a wide range of operating temperatures. A low modulus of elasticity for the brake lining materials is also desired, so that they can conform to the shape of the counter disc/drum. The maximum operating temperature (MOT) for brake lining materials must be large enough to prevent thermal degradation of the surface, and it is, by design, lower than the MOT of the brake disc/drum materials. Additionally, brake lining materials must possess low thermal conductivity to prevent heat conduction to other
$A_{\text {s }} \quad$ Contact area at test specimen-counter disc interface $\left(\mathrm{m}^{2}\right)$

$\sigma$ bs Normal stress on the brake shoe (MPa)

$\sigma_{\mathrm{s}} \quad$ Normal stress on the test specimen (MPa)

$b \quad$ Wheelbase of the vehicle $(\mathrm{m})$

$x \quad$ Horizontal distance of the center of gravity of the vehicle from the rear tire center

$y \quad$ Vertical distance of the center of gravity of the vehicle from the ground level

$T_{\mathrm{s}} \quad$ Temperature at the test specimen-counter disc interface $\left({ }^{\circ} \mathrm{C}\right)$

$\rho \quad$ Density of the test specimen material $\left(\mathrm{kg} / \mathrm{m}^{3}\right)$

$\Delta m$ Reduction in mass of the test specimen $(\mathrm{kg})$

$S_{\mathrm{s}} \quad$ Stopping distance of the vehicle after application of brake (m)

$S_{t} \quad$ Running distance for the wear test (m)

$\tilde{V} \quad$ Specific rate of volumetric loss of brake lining material $\left(\mathrm{m}^{3} /(\mathrm{N} \cdot \mathrm{m})\right)$ components of the actuating mechanism such as the s-cam shafts, slack adjuster, brake chambers, and especially, the brake fluids [2].

Waste or discarded tires made of vulcanized synthetic rubber or natural rubber pose a major ecological threat owing to their non-biodegradable nature. Their disposal and management have emerged as a worldwide concern. Current methods of disposal involve landfilling, thermochemical conversion, incineration, and fuel or chemical recovery through gasification or pyrolysis [3]. The incineration of waste tires leads to the emission of highly toxic and polluting gases, which only facilitates the transformation of land pollution into air pollution. Recent efforts have been directed towards reusing tire waste in cementitious materials in which rubber particles of optimum size and proportion are known to offer an improvement in the toughness and damping capability of those materials [4]. In the present work, discarded tires are reused in the form of waste tire rubber particulates (WTRPs) as micro-fillers in brake linings and their effects on the mechanical, friction, and wear characteristics of brake lining materials are studied.

Brake lining materials consist of a binder, frictional modifiers, reinforcing fibers, and fillers. Commonly used binders include phenolic resin, cashew nut shell 
liquid, epoxy, polyester, and their blends [1, 5-7]. Frictional modifiers comprise lubricants and abrasives. Metallic sulfides and graphite are commonly used dry lubricants, whereas metallic carbides and oxides are employed as abrasives [6, 7]. Various fibers have been used to reinforce the binder, such as inorganic (lapinus), organic (Kevlar/aramid), ceramic (aluminumsilicon, glass), metallic (copper), and natural fibers (cellulosic) [5-10]. Widely used fillers include alumina, silica, calcium carbonate, talc, and barium sulfate $[6-8,11]$. The fabrication techniques for brake linings include compression molding (polymer matrix, i.e., resin-based binders) and sintering (metallic matrix$\mathrm{Cu}, \mathrm{Fe}$, and Ni alloys) [1, 5-8, 11-13].

The scope of suitable filler materials in brake linings that augment the tribological and mechanical performance is significant. However, WTRPs as filler additives in brake friction linings have not been previously explored, and based on studies, the high carbon content of tire rubber particles would provide vibration damping, higher resistance to shock, acoustic advantages, and a cushioning effect. Herein, we evaluated the potential of waste tire rubber particulates as fillers in brake lining. In addition to the WTRPs as fillers, the brake linings included phenolic-resol resin as the binder, graphite as the dry lubricant, laterite as co-fillers, and treated coconut coir (whisker) for natural fiber reinforcement. The content of WTRPs was increased from 8 to $15 \mathrm{wt} \%$ to deduce their contribution to the wear and frictional behavior of the linings. Because the mechanical responses of brake lining materials are essential for operation, mechanical characterizations including the compressive test, hardness test, density, and porosity measurement were conducted. Additionally, as the maximum or peak operating temperature plays an important role in the wear of brake linings, the thermal response of the brake linings was analyzed. The temperature rise was duly monitored during tribological studies and the extent of temperature rise with continuous operation was determined.

\section{Materials and methods}

\subsection{Fabrication of brake lining materials}

The constituents of the brake lining material, specifically phenolic-resol resin (Supplier: Akolite Synthetic Resins, Bykampady, Mangalore), WTRPs (Supplier: Long Age Treading, Udupi), graphite particulates $\sim 75 \mu \mathrm{m}$ (Supplier: M/s. Specialty Graphites, Puttur), p-toluene Sulfonic acid (Supplier: M/s SDFCL, Mumbai) were sourced, whereas the coconut coir whiskers ( $75 \mu \mathrm{m}$ diameter, 2 to $3 \mathrm{~cm}$ in length) and laterite dust (rinsed, dried, crushed, and screened through an ASTM 200 mesh sieve $\sim 75 \mu \mathrm{m}$ ) were procured locally. The role of p-toluene sulfonic acid is to accelerate the formation of methylene bridges during polymerization. Coconut coir whiskers were placed in a $2 \mathrm{wt} \% \mathrm{NaOH}$ solution for $2 \mathrm{~h}$ at room temperature of $30{ }^{\circ} \mathrm{C}$, the absorbed alkali was then leached by washing the coir whiskers in distilled water and finally, the whiskers were dried in a hot air oven at $70{ }^{\circ} \mathrm{C}$. This treatment is necessary for natural fibers such as coconut coir to ensure defatting occurs, which increases density, improves fiber-resin interfacial bonding, and removes the hemicellulosic components [14]. Table 1 shows the weight fractions of the different constituents used for the fabrication of the brake linings. WTRPs as microfillers are expected to improve the acoustic and vibration damping of the brake linings. However, increased brake lining hardness is observed at higher WTRP weight fractions. This would negatively affect the surface deformation characteristics by hindering the ability to form proper contact with the brake disc. This, in turn, would increase the load necessary to hold the brake lining against the counter face disc. Hence, the maximum WTRP weight percentage was limited to $15 \%$ by weight. Three compositions of brake lining materials, named W-I, W-II, and W-III, were fabricated.

Table 1 Constituents of the different compositions.

\begin{tabular}{ccccc}
\hline Constituent & Role & W-I & W-II & W-III \\
\hline WTRPs (wt $\%)$ & Filler & 0 & 8 & 15 \\
$\begin{array}{c}\text { Phenolic resin (wt } \%) \\
\begin{array}{c}\text { Coconut coir whisker } \\
(w t \%)\end{array}\end{array}$ & Binder & 35 & 35 & 35 \\
$\begin{array}{c}\text { p-toluene sulfonic acid } \\
(w t \%)\end{array}$ & Hardener & 5 & 5 & 5 \\
$\begin{array}{c}\text { Graphite particulates } \\
(w t \%)\end{array}$ & $\begin{array}{c}\text { Friction modifier- } \\
\text { dry lubricant }\end{array}$ & 15 & 15 & 15 \\
$\begin{array}{c}\text { Laterite fines }(w t \%) \\
\text { Friction modifier }\end{array}$ & 30 & 22 & 15 \\
\hline
\end{tabular}


For fabrication, a customized steel mold of inner dimensions $15 \mathrm{~cm} \times 15 \mathrm{~cm} \times 2 \mathrm{~cm}$ and a top plate of dimensions $14.9 \mathrm{~cm} \times 14.9 \mathrm{~cm} \times 3 \mathrm{~cm}$ were used. The interior of the mold was cleaned with acetone, and then a peel ply along with aluminum foil was placed inside the mold to aid in the removal of the part after compaction. The hardener, p-toluene sulfonic acid, was premixed with the phenolic resin, and set aside for $5 \mathrm{~min}$. The graphite particulates, WTRPs, and laterite fines, were put into a burr mill mixer and a portion was uniformly dispensed into the mold. A portion of the coir fibers were then added with random orientation, as shown in Fig. 1(a). A thin layer of the hardener-resin mixture was poured onto the coir layer. This procedure was repeated until the desired weighed quantities of each constituent were achieved. After covering the layer with foil, the top plate was secured on top of the mold. The assembly was then placed inside the compression molding machine, as shown in Fig. 1(b). Compression was carried out at a pressure of $14 \mathrm{MPa}$ and a temperature of $160{ }^{\circ} \mathrm{C}$ for $10 \mathrm{~min}$. The assembly was then placed inside a hot air oven at $160{ }^{\circ} \mathrm{C}$ to allow post-curing for $5 \mathrm{~h}$. The commercial brake lining RANE P2 29G1S, which is designed for vehicles of gross weight less than 16 tons, was purchased to act as a benchmark against which the fabricated brake linings will be compared. It is labeled as W-IV in the different studies.

\subsection{Estimation of wear parameters}

The fabricated brake linings were intended for commercial vehicles of gross vehicle weight $\leq 16$ tons. To replicate real-time braking conditions in the experimental setup, the parameters affecting a typical braking event were analyzed, namely the speed, normal load, coefficient of friction at the tire-road interface and at the brake lining-drum interface, wheelbase, location of the vehicle's center of gravity, and interface areas. The evaluations of load distribution, road reaction, and braking effort are presented in the appendix.

For safe operation of the vehicle without skidding (brake slip < 20\%) [2], the coefficient of friction at the tire-road interface $\left(\mu_{\mathrm{t}}\right)$ was limited to $\sim 0.5$. The load $\left(F_{\mathrm{bs}}\right)$ acts on the curved surface area of the brake shoe $\left(A_{\mathrm{bs}}\right)$ which leads to radial stress $\left(\sigma_{\mathrm{bs}}\right)$ on the brake shoe. The relationship between these parameters is expressed in Eq. (1). A reduced-scale prototype (RSP) cut from the fabricated linings and commercial brake shoe was used for characterization [15]. The contact area of the test specimen to the counter disc is denoted as $A_{\mathrm{s}}$. When the dimensions of the RSP wear-test specimen are small such that $A_{\mathrm{s}} \ll A_{\mathrm{bs},}$ the radial stress can be taken as a normal stress $\left(\sigma_{\mathrm{s}}\right)$ on the test specimen. Figure 2(a) shows the measurements of $A_{\mathrm{s}}$ whereas Fig. 2(b) shows the wear test specimen setup. The value of $A_{\mathrm{bs}}$ was measured as $0.027 \mathrm{~m}^{2}$ and the value of $A_{\mathrm{s}}$ was $3.6 \times 10^{-5} \mathrm{~m}^{2}$. To replicate actual load conditions in the experimental setup, the value of $\sigma_{\mathrm{bs}}$ was assumed to equal to $\sigma_{s}$. The normal load on the specimen $\left(F_{\mathrm{s}}\right)$ is calculated using Eq. (2) and the different values of $F_{\mathrm{s}}$ for varying values of $\mu_{\mathrm{b}}\left(1>\mu_{\mathrm{b}} \geq 0\right)$ are shown in Table 2 .

The deceleration of the vehicle $(\alpha)$ depends on the coefficient of friction at the tire-road interface $\left(\mu_{\mathrm{t}}\right)$
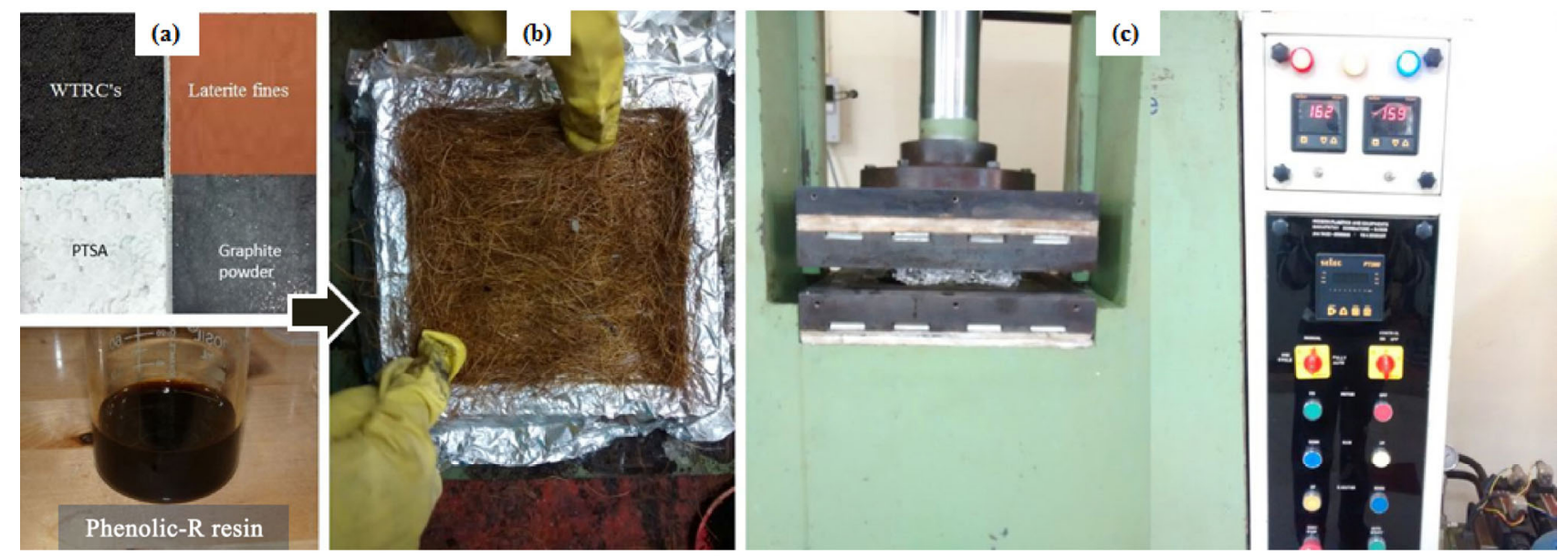

Fig. 1 (a) Constituents for brake lining material; (b) layup in mold; and (c) compression molding. 
(a)

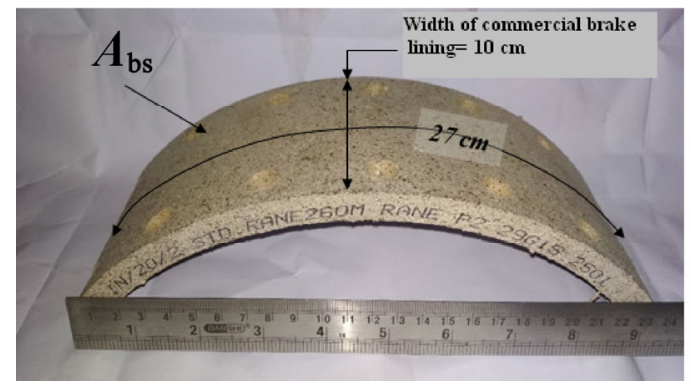

(b)

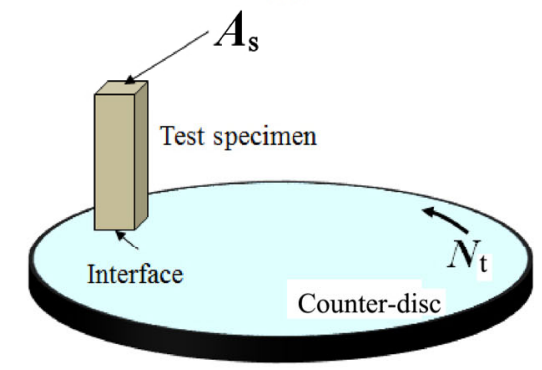

Fig. 2 (a) Measurement of $A_{\text {bs }}$ for commercial brake shoe. (b) Wear test setup.

Table 2 Estimation of normal force " $F_{\mathrm{s}}$ ".

\begin{tabular}{ccccc}
\hline$\mu_{\mathrm{b}}$ & $\begin{array}{c}F_{\mathrm{bs}} \\
\left(\times 10^{4} \mathrm{~N}\right)\end{array}$ & $\begin{array}{c}\sigma_{\mathrm{bs}} \\
(\mathrm{MPa})\end{array}$ & $\begin{array}{c}F_{\mathrm{s}} \\
(\mathrm{N})\end{array}$ & $\begin{array}{c}F_{\mathrm{s}} \\
(\mathrm{kg})\end{array}$ \\
\hline 0.10 & 19.6 & 7.27 & 261.6 & 26.7 \\
0.20 & 9.81 & 3.63 & 130.8 & 13.3 \\
0.30 & 6.54 & 2.42 & 87.2 & 8.9 \\
0.40 & 4.91 & 1.82 & 65.4 & 6.7 \\
0.50 & 3.92 & 1.45 & 52.3 & 5.3 \\
0.60 & 3.27 & 1.21 & 43.6 & 4.4 \\
0.70 & 2.80 & 1.04 & 37.3 & 3.8 \\
0.80 & 2.45 & 0.91 & 32.7 & 3.3 \\
0.90 & 2.18 & 0.81 & 29.0 & 2.9 \\
1.00 & 1.96 & 0.73 & 26.2 & 2.7 \\
\hline
\end{tabular}

and the acceleration due to gravity (g) (Eq. (3)) and in turn on the coefficient of friction at the brake liningdrum interface $\left(\mu_{\mathrm{b}}\right)$ (Eq. (A4)). Because the stopping distance is inversely proportional to the deceleration, lower values of $\mu_{\mathrm{b}}$ would reduce the deceleration and increase the stopping distance, which could lead to an accident [16]. To minimize the stopping distance of the vehicle $\left(S_{s}\right)$ (Eq. (4)) for a vehicle speed " $U$ ", it was specified that $\mu_{\mathrm{b}} \geq 0.3$. Therefore, the normal load on the specimen $\left(F_{\mathrm{s}}\right)$ was taken as $3 \mathrm{~kg}(29.4 \mathrm{~N}), 6 \mathrm{~kg}$ $(58.8 \mathrm{~N})$, and $9 \mathrm{~kg}(88.2 \mathrm{~N})$ for the wear test.

$$
\begin{gathered}
\sigma_{\mathrm{bs}}=\frac{F_{\mathrm{bs}}}{A_{\mathrm{bs}}} \\
F_{\mathrm{s}}=\sigma_{\mathrm{s}} \times A_{\mathrm{s}}=\sigma_{\mathrm{bs}} \times A_{\mathrm{s}} \\
\alpha=\mu_{\mathrm{t}} g \\
S_{\mathrm{s}}=\frac{U^{2}}{2 \alpha}
\end{gathered}
$$

To determine the range of speeds for the wear test, the range of engine speed $\left(N_{\mathrm{E}}\right)$, gear ratios, rear axle ratios, and wheel size dimensions were considered. Six-cylinder inline-diesel engines with $\sim 6,000$ cc capacity generally operate between 600 RPM (idling) and 3,000 RPM (max speed), hence the engine speed range was set between 600 and 3,000 RPM. Due to the transmission-gearbox and rear axle drives, there is a reduction in the speed when the engine drive is transmitted to the wheels. To determine the wheel speed, a six-speed gearbox with overdrive gear (first gear ratio 6.5:1) and rear axle drive (rear axle ratios varying from $4: 1$ to $6: 1$ ) have been considered. For a six-speed gearbox, the minimum engine speed that can be employed would be in the $1^{\text {st }}$ gear, and the engine speed can reach 1,000 RPM before necessitating a gear shift to the $2^{\text {nd }}$ gear. The top gear (in this case the $5^{\text {th }}$ gear), as well as the overdrive gear ( $6^{\text {th }}$ gear), would correspond to the maximum engine speed. Table 3 gives the wheel speed estimates $\left(N_{t}\right)$ and vehicle speed $(U)$ for different gearbox and rear axle ratios. After regularizing the values of $N_{\mathrm{t}}$, the values of the wheel speed for the wear test were chosen as 50,425, and 800 RPM.

\subsection{Characterization of microstructure, mechanical, and tribological performances}

The microstructure of the fabricated composites was studied using the trinocular optical microscope (METJI M 1004). Because brake linings are compressed against the disc during braking, their strength retention under compression must be studied. Hence, compressive tests were conducted, as detailed in Fig. 3(a). The brake linings also need to exhibit a certain level of surface hardness to resist deformation upon contacting the counter disc surface. Because the sizes of the additives 
Table 3 Estimation of wheel speed " $N_{\mathrm{t}}$ " and vehicle speed " $U$ ".

\begin{tabular}{cccccccc}
\hline$N_{\mathrm{E}}(\mathrm{RPM})$ & Gear number & Gear ratio & $N_{\mathrm{p}}(\mathrm{RPM})$ & Rear axle ratio & $N_{\mathrm{t}}(\mathrm{RPM})$ & $U(\mathrm{~m} / \mathrm{s})$ & $U(\mathrm{~km} / \mathrm{h})$ \\
\hline 600 & $1^{\text {st }}$ & $6.5: 1$ & 92.3 & $4: 1$ & 23.1 & 0.6 & 2.2 \\
1,000 & $1^{\text {st }}$ & $6.5: 1$ & 153.8 & $4: 1$ & 38.5 & 1 & 3.7 \\
3,000 & $5^{\text {th }}$ & $1: 1$ & 3,000 & $4: 1$ & 750 & 19.9 & 71.8 \\
3,000 & Over drive & $0.8: 1$ & 3,750 & $4: 1$ & 937.5 & 24.9 & 89.8 \\
600 & $1^{\text {st }}$ & $6.5: 1$ & 92.3 & $5: 1$ & 18.5 & 0.5 & 1.8 \\
1,000 & $1^{\text {st }}$ & $6.5: 1$ & 153.8 & $5: 1$ & 30.8 & 0.8 & 2.9 \\
3,000 & $5^{\text {th }}$ & $1: 1$ & 3,000 & $5: 1$ & 600 & 15.9 & 57.4 \\
3,000 & Over drive & $0.8: 1$ & 3,750 & $5: 1$ & 750 & 19.9 & 71.8 \\
600 & $1^{\text {st }}$ & $6.5: 1$ & 92.3 & $6: 1$ & 15.4 & 0.4 & 1.5 \\
1,000 & $1^{\text {st }}$ & $6.5: 1$ & 153.8 & $6: 1$ & 25.6 & 0.7 & 2.5 \\
3,000 & $5^{\text {th }}$ & $1: 1$ & 3,000 & $6: 1$ & 500 & 13.3 & 47.9 \\
3,000 & Over drive & $0.8: 1$ & 3,750 & $6: 1$ & 625 & 16.6 & 59.8 \\
\hline
\end{tabular}
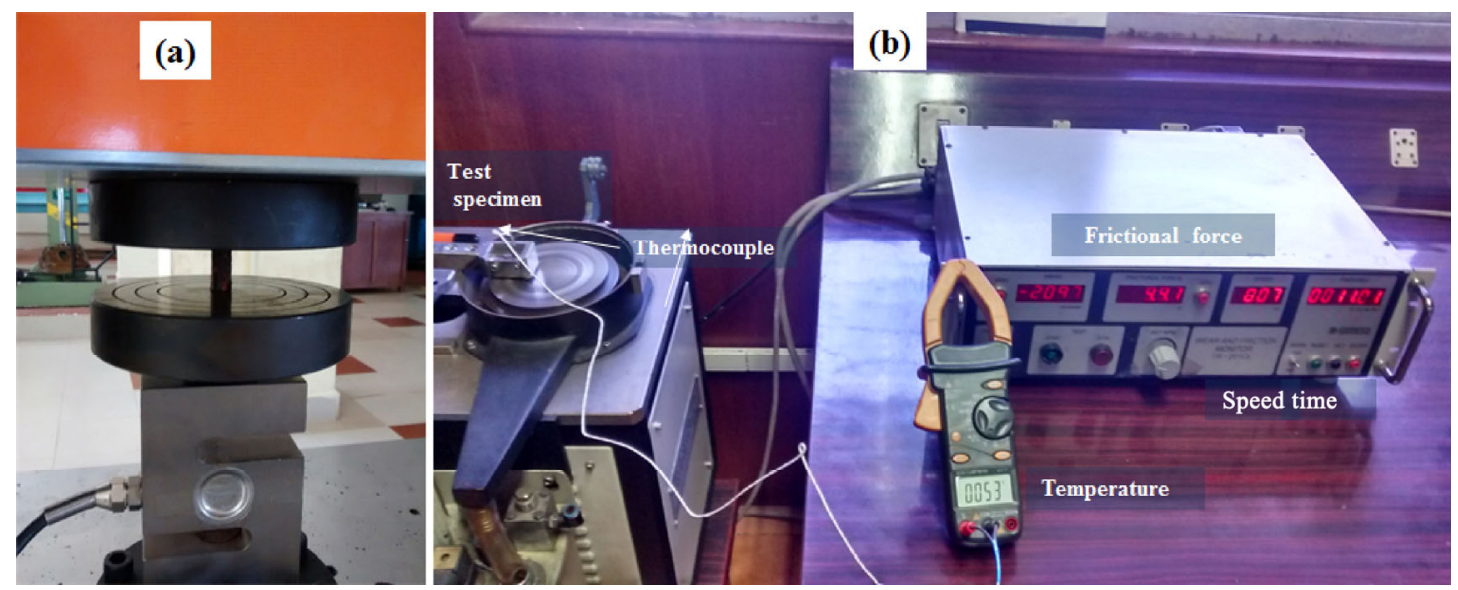

Fig. 3 (a) Compression test setup and (b) pin-on-disc tribometer.

used, such as the laterite and WTRP fillers and the graphite dry lubricant, were in the micron scale, a single macro hardness test conducted on the fabricated brake lining materials would not be an accurate representation of the resistance of the surface to deformation. Thus, the Micro-Vickers hardness test was conducted at 10 locations on each specimen. To ascertain the quality of the fabricated materials, density, and porosity measurement was conducted. The porosity or void content measurement was recorded as per the ASTM D2734-94 standard [17]. Table 4 details the different tests including the equipment used, specimen details, and the corresponding ASTM standards.

Figure 3(b) shows the pin-on-disc tribometer (DUCOM TR-201CL) used for tribo-studies of the brake lining materials $[2,13,18-20]$. The EN-31 hardened steel disc $(\phi 100 \mathrm{~mm} \times 7 \mathrm{~mm})$ was employed as the counter face, with the flatness and runout on the wear disc holder $\leq 20 \mu \mathrm{m}$. The disc was cleaned with acetone to remove contaminants. The RSP wear specimen was mounted on a single bar holder with wire rope and a loading pan for dead weights was fixed with pivot point at the center for 1:1 leverage. The tests were conducted at three angular speeds: 5.23, 44.5, and $83.8 \mathrm{rad} / \mathrm{s}$. With an $80 \mathrm{~mm}$ sector diameter used for tribo-contact, the corresponding peripheral speeds were $0.2,1.8$, and $3.3 \mathrm{~m} / \mathrm{s}$, respectively. The crosssectional area of the RSP wear specimen was $36 \mathrm{~mm}^{2}$, and the normal loads employed were 29.4, 58.8, and $88.2 \mathrm{~N}$, corresponding to the pressure values of 0.82 , 1.63 , and $2.45 \mathrm{MPa}$, respectively, which are varied 
Table 4 Details of experimental setup and standards.

\begin{tabular}{ccccr}
\hline & Compression testing & Density measurement & $\begin{array}{c}\text { Hardness testing } \\
\text { (micro-vickers) }\end{array}$ & Wear testing \\
\hline ASTM standard & ASTM D695-15 [40] & ASTM D792-13 [41] & ASTM E384-16 [42] & ASTM G99-05 [24] \\
Equipment & UNITEK 9450 & $\begin{array}{c}\text { IMMERSION VESSEL } \\
\text { W/O SINKER }\end{array}$ & MATSUZAWA MMT-X & DUCOM TR-201CL \\
Specimen dimensions (mm) & $12.7 \times 12.7 \times 25.4$ & $12.7 \times 12.7 \times 25.4$ & $20 \times 20 \times 3$ & $6 \times 6 \times 30$ \\
No. of specimens & 5 & 5 & 9 & 2 per composition \\
\hline
\end{tabular}

discretely for each test run. Because a preset pressure would remain active throughout $\sim 100 \%$ ( $\geq 95 \%)$ of the wear test, pin-on-disk wear tests enable continuous monitoring of the instantaneous coefficient of friction. The AC motor driving the spindle and counter face disc compensates for any slowdown in speed by increasing the power to the disc, and thus the assessment of brake stops (slow down to less than $0.5 \mathrm{~km} / \mathrm{h}$ or $0.14 \mathrm{~m} / \mathrm{s}$ ) or brake snubs (slow down to $\sim 5 \mathrm{~km} / \mathrm{h}$ or $1.4 \mathrm{~m} / \mathrm{s}$ ) was limited in the current tribometer setup, which would not be the case in a brake inertia dynamometer setup [21, 22]. However, the continuous contact of the tribo-couple at the preset pressure (without slowdown) can be utilized to analyze the thermal fade characteristics with intentional heating at the interface. A thermocouple was secured at the interface and the measurement of temperature was continuously monitored along with the coefficient of friction for each run [23]. The weight loss of the RSP wear specimen was measured after each run and the specific rate of volumetric loss for the specimen was determined from Eq. (5) [24].

$$
\tilde{V}=\frac{\Delta m}{\rho F_{\mathrm{s}} S_{\mathrm{t}}}
$$

\section{Results and discussion}

\subsection{Mechanical characterization and microstructure}

The mechanical properties of the compositions are presented in Table 5. As the WTRP content increased, the mass density, porosity, and hardness decreased. The reduction in mass density was not due to porosity or interstitial gaps at the boundaries of the constituents but rather due to the lower density of WTRP fillers, as evident from the micrographs. This is an advantage as reducing the brake lining weight would reduce the inertia of the brake liners during brake release [25]. The reduction in porosity can be attributed to the elastomeric nature of the WTRPs and the enhancing effect of the phenolic resin on WTRP cross-linking. This improved the interfacial adhesion and allowed a higher degree of packing to be achieved during the compression molding process and the curing stage $[26,27]$. The hardness of W-III was estimated to be $\sim 70 \%$ of the commercial lining's W-IV, whereas the compressive strength of W-III was $\sim 91 \%$ of W-IV. Because WTRPs are softer than the other constituents, an increase in the WTRP weight fraction leads to a reduction in the hardness because hardness is a surface phenomenon. In contrast, the compressive strength, as a volumetric property, was found to increase with higher WTRP content. This behavior could be attributed to the elastomeric nature of WTRPs that when embedded in the cured matrix are capable of absorbing more load without significant plastic deformation (Poisson's ratio of tire rubber: $~ 0.3$ ) [6, 28]. The correlation between Micro-Vickers hardness and compressive strength has been reported in previous literature in which the type of filler material is critical to the material response. Hard materials such as yttria, copper, and aluminum particles tend to show a positive correlation (beyond a certain mass fraction in the composite) between the hardness and compressive strength, whereas softer materials such as rubber would show a negative correlation [29-31]. The specific compressive strength of W-III $(2.26 \mathrm{~km})$ was greater than that of the commercial lining W-IV $(2.21 \mathrm{~km})$, which further indicates the advantage in terms of the strength-to-weight ratio. All brake linings must be mechanically sound prior to being subjected to the wear test to prevent premature mechanical failure of the brake lining during operation [25]. 
Table 5 Mechanical and physical properties.

\begin{tabular}{|c|c|c|c|c|}
\hline Property & W-I & W-II & W-III & W-IV \\
\hline Density $\left(\mathrm{kg} / \mathrm{m}^{3}\right)$ & 1,630 & 1,620 & 1,615 & 1,805 \\
\hline Specific weight $\left(\mathrm{kN} / \mathrm{m}^{3}\right)$ & 15.99 & 15.89 & 15.84 & 17.71 \\
\hline Porosity $(\%)$ & 5.67 & 5.25 & 4.98 & - \\
\hline Micro Vickers hardness & $46 \mathrm{HV} 0.1$ & $42 \mathrm{HV} 0.1$ & $38 \mathrm{HV} 0.1$ & $54 \mathrm{HV} 0.1$ \\
\hline Compressive strength (MPa) & 22.4 & 30.3 & 35.8 & 39.2 \\
\hline Specific compressive strength $(\mathrm{km})$ & 1.40 & 1.91 & 2.26 & 2.21 \\
\hline
\end{tabular}

The microstructure of the four compositions considered for studies is displayed in Fig. 4. From the optical micrographs, the laterite, WTRP, and graphite fillers were randomly distributed within the phenolic resin matrix. Post-curing, no cracks or discontinuities were noticed within the material. From the microstructure of the commercial brake lining W-IV, it appears that coarser fillers were utilized in the binder matrix and, similar to the fabricated brake linings, the distribution appeared to be random.

\subsection{Tribological performance}

Figures 5, 6, 7, and 8 contain the contour maps for the coefficient of friction $\left(\mu_{\mathrm{b}}\right)$ and interface temperature $\left(T_{\mathrm{s}}\right)$ relative to normal load and time for W-I, W-II, $\mathrm{W}-\mathrm{III}$ and $\mathrm{W}-\mathrm{IV}$, respectively. In all the compositions, the coefficient of friction was found to decrease with an increase in speed whereas friction was found to increase with load. The maxima of the coefficient of friction for all the compositions were observed at $50 \mathrm{RPM}$ and $9 \mathrm{~kg}$ of normal load. As the WTRP weight content increased, there was an increase in the coefficient of friction with the highest value of 0.38 recorded for the W-III composition. This is slightly lower than that of the commercial lining W-IV, which was 0.41 . The average coefficients of friction for the different compositions are displayed in Fig. 9. The average coefficients of friction were found to increase with load for all the three speeds tested $(0.2,1.8$, and $3.3 \mathrm{~m} / \mathrm{s})$. The highest values of the average coefficient of friction were observed at the middle speed range of $1.8 \mathrm{~m} / \mathrm{s}$. With increasing WTRP content, the mean

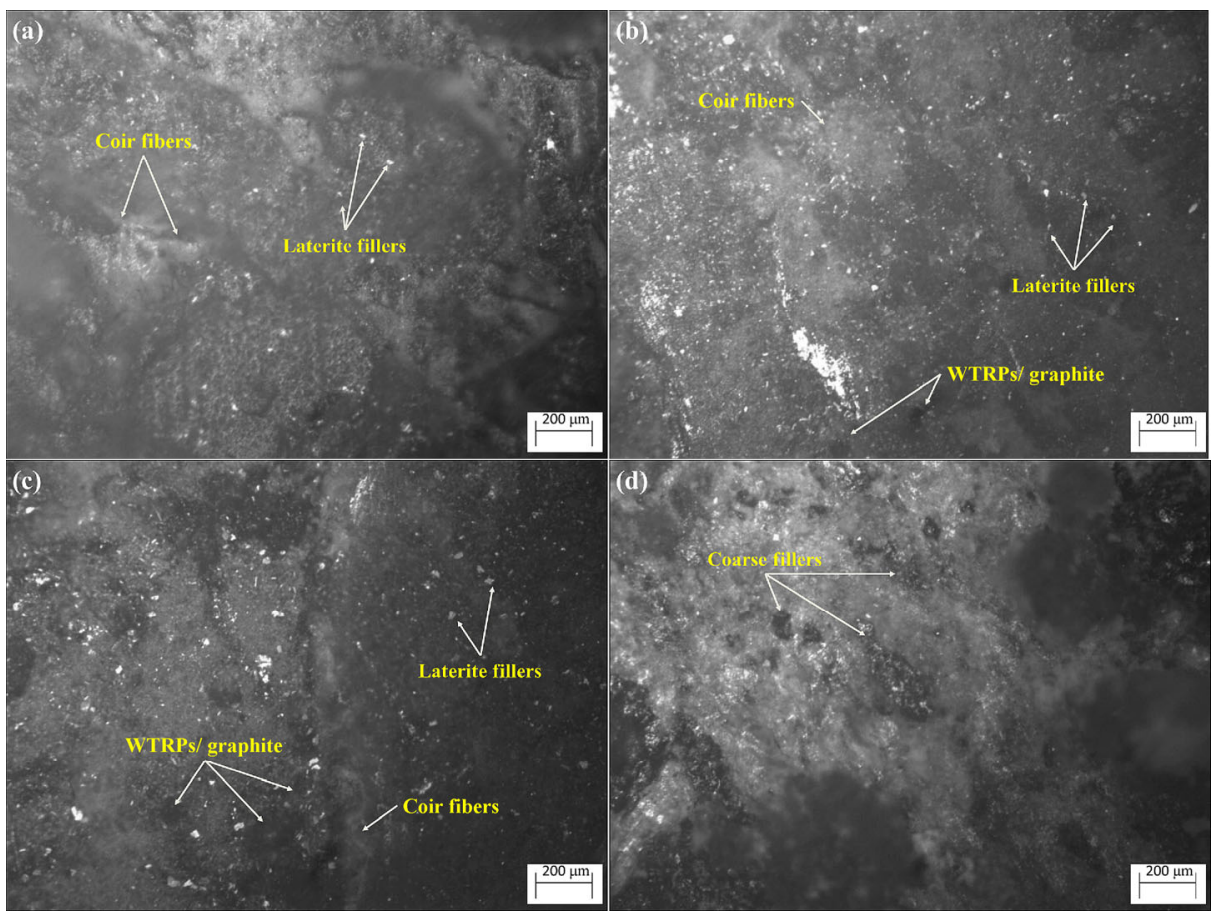

Fig. 4 Optical micrographs: (a) W-I, (b) W-II, (c) W-III, and (d) W-IV. 

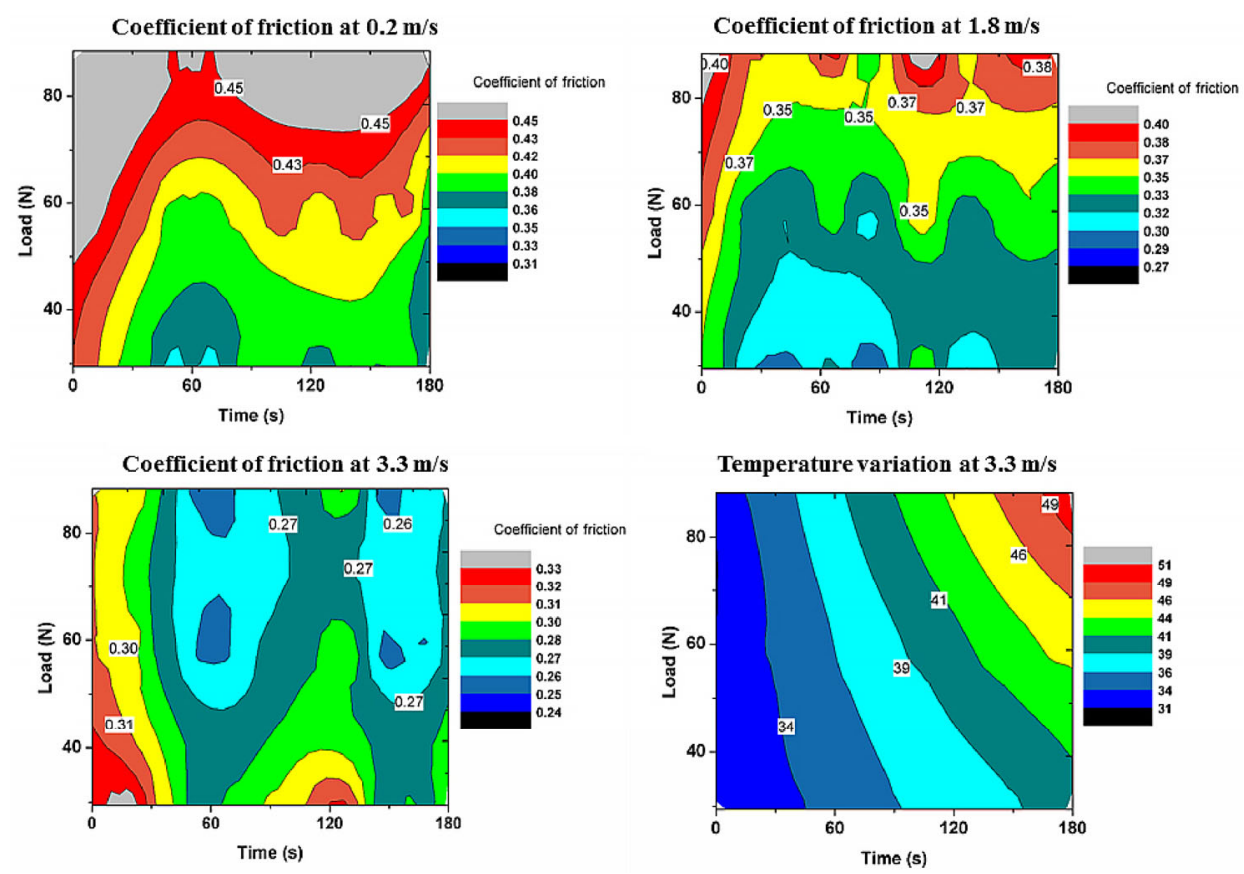

Fig. 5 Variation of the coefficient of friction and temperature for the W-I composition.
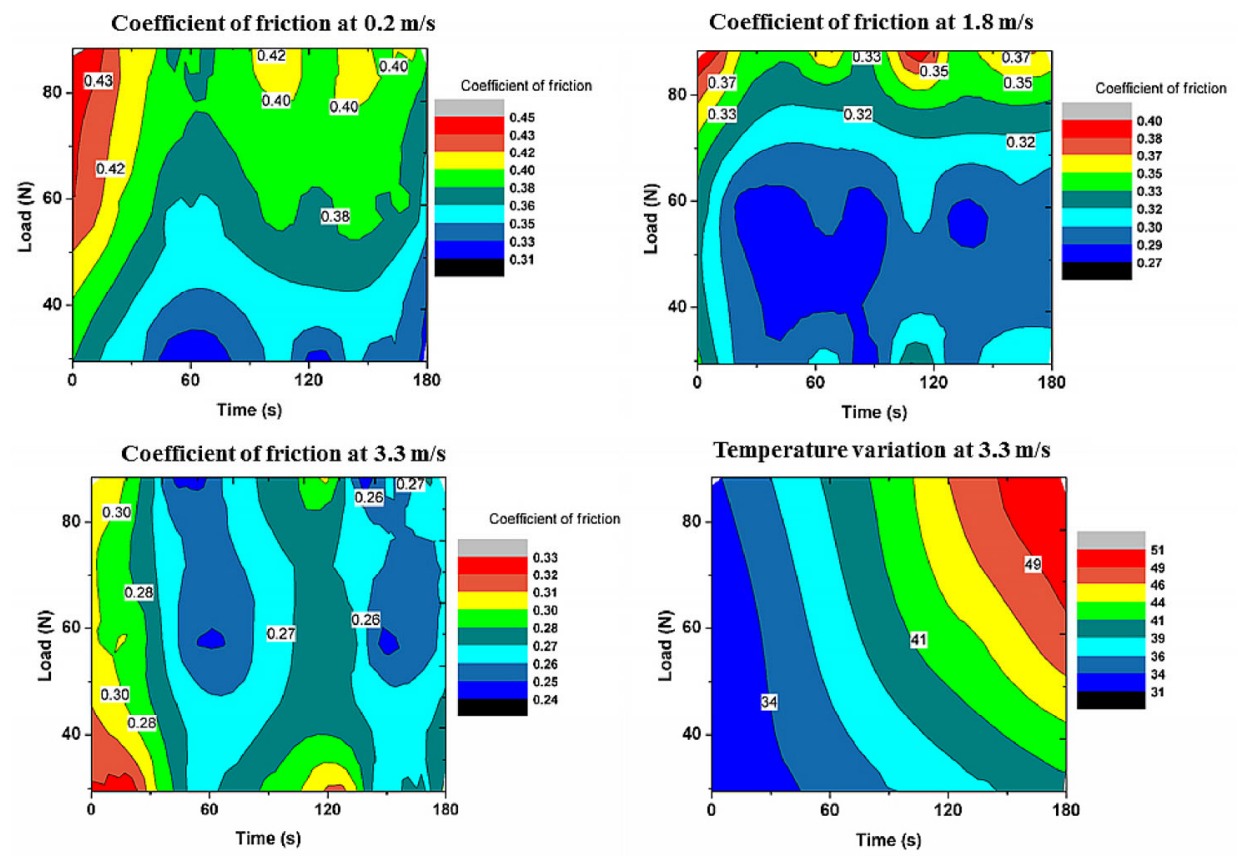

Fig. 6 Variation of the coefficient of friction and temperature for W-II composition.

coefficient of friction $\left(\mu_{\text {mean }}\right)$, computed across all speeds and loads, was found to increase. The $\mu_{\text {mean }}$ was 0.38 for the W-III composition. For $\mu_{\mathrm{b}}=0.38$, the range of normal stress of the brake shoe would be $1.82 \mathrm{MPa} \leq \sigma_{\mathrm{bs}} \leq 2.42 \mathrm{MPa}$, and with a compressive strength of 35.2 MPa for W-III, the brake lining would be operating with a safety factor of $\sim 14$ to 20 . The frictional performance exhibited by the WTRP-based linings was in agreement with recent brake linings reported in Refs. [2, 19, 32]. The variation in the coefficient of friction can be attributed to the rate and location of release of particles in the form of wear debris. Additionally, the loosening of filler particles can contribute to three-body wear and the build-up 

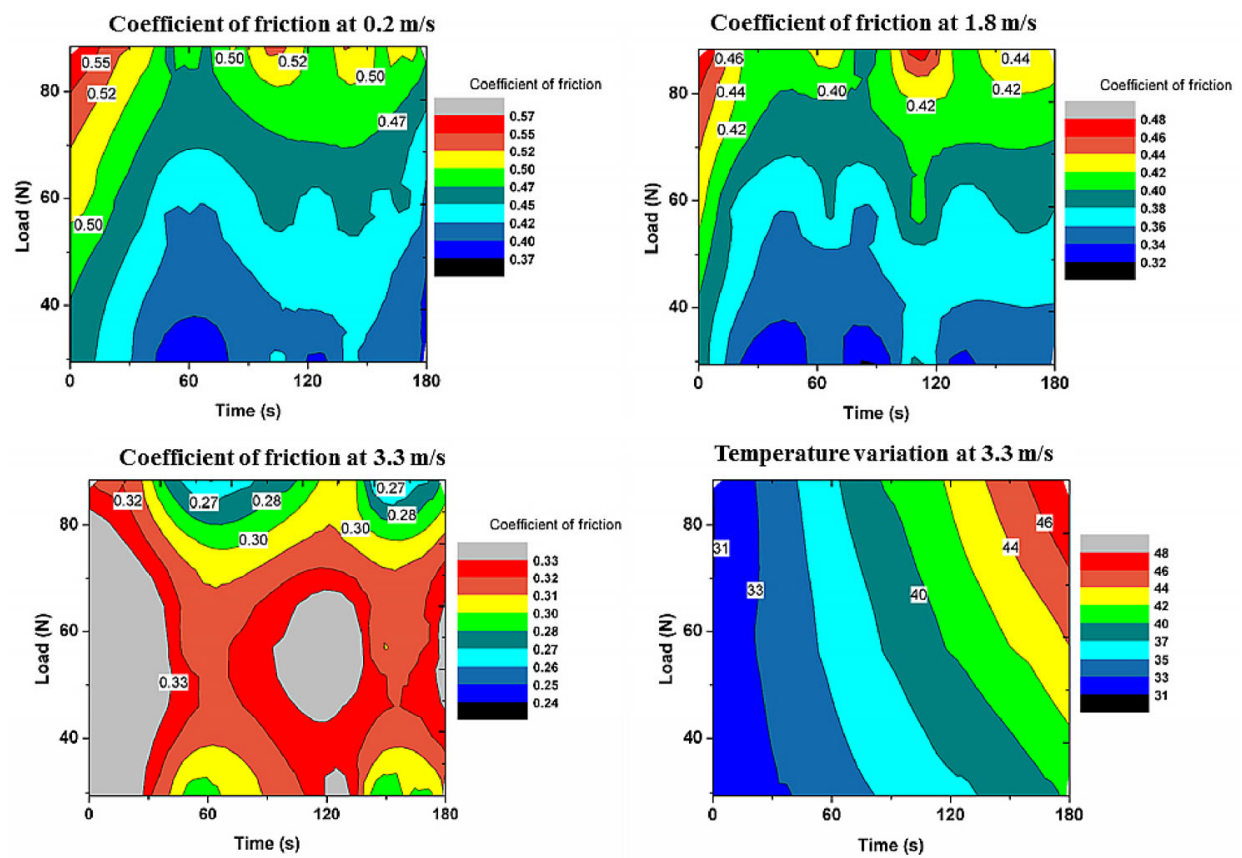

Fig. 7 Variation of the coefficient of friction and temperature for W-III composition.
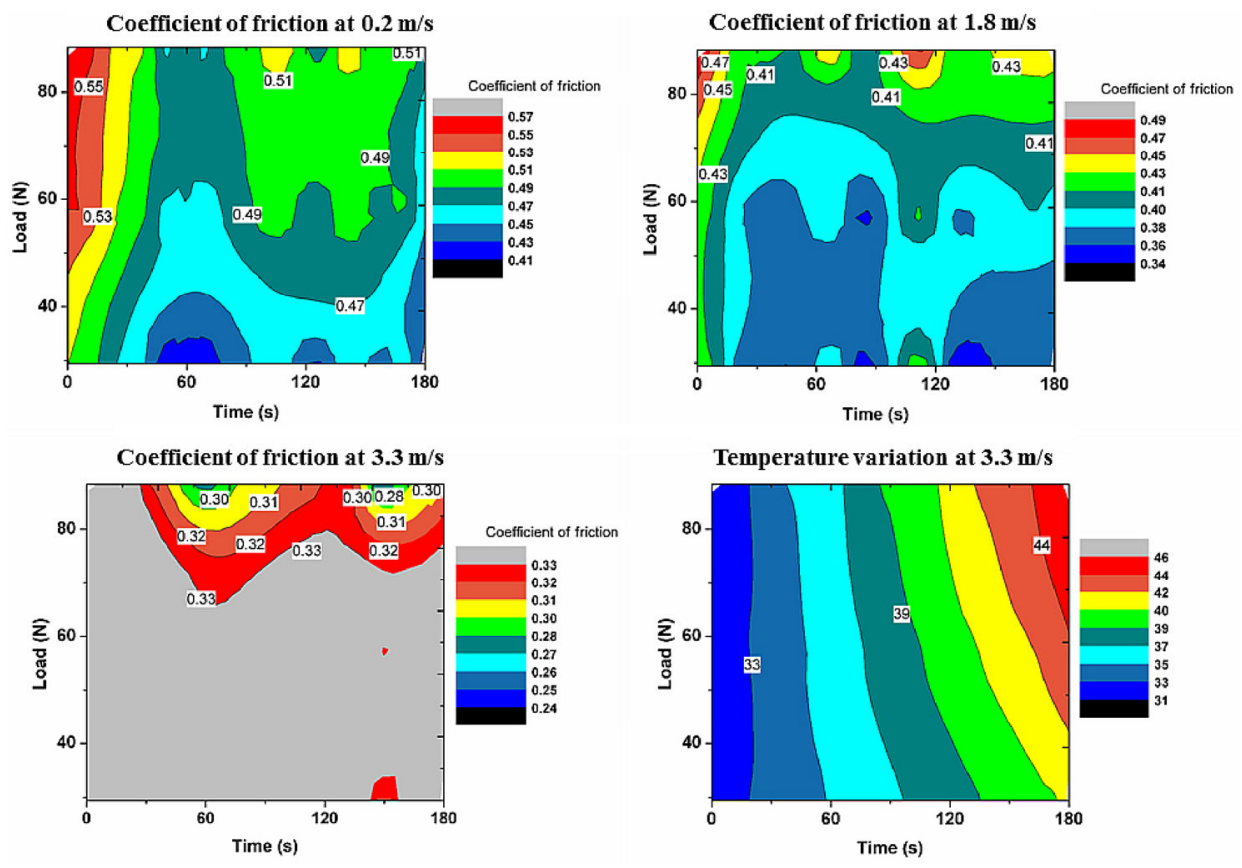

Fig. 8 Variation of the coefficient of friction and temperature for W-IV composition.

and breakdown of primary or secondary plateaus because the rate of plastic deformation intensifies at higher speeds [18, 20, 33].

For all the compositions, the temperature rise accelerated as the load increased. At higher loads, an increase in the coefficient of friction was observed, indicating an augmented asperity-to-asperity inter- action. In turn, more friction led to greater heat generation that was responsible for faster temperature rise. At peak speed, less time was available for heat dissipation from the tribo-interface, which caused a steep increase in temperature as observed in the temperature maps of the different compositions at $3.3 \mathrm{~m} / \mathrm{s}$. The highest temperature peak at $53{ }^{\circ} \mathrm{C}$ was observed 
(a)

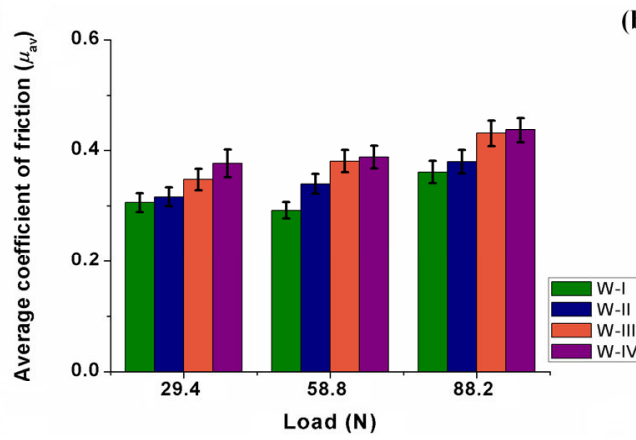

(c)

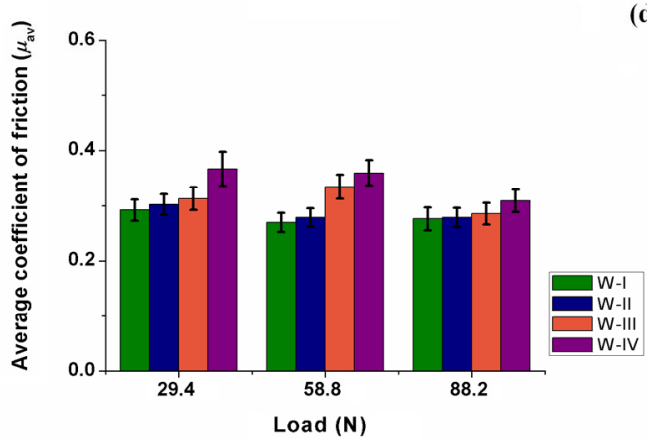

(b)

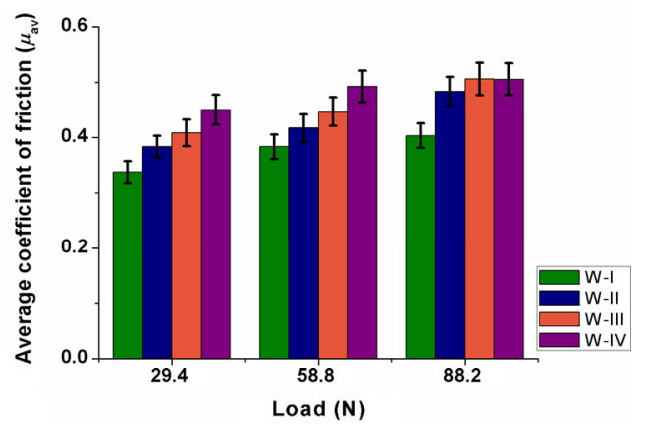

(d)

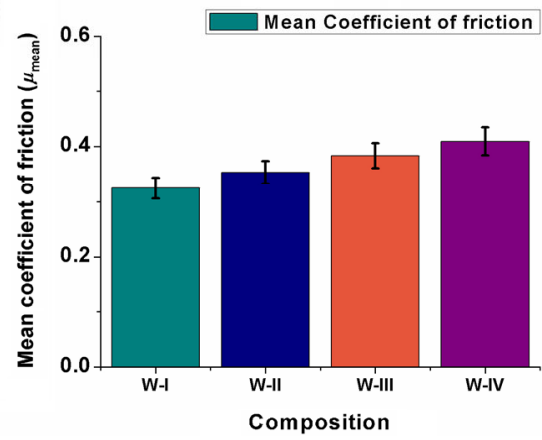

Fig. 9 Average coefficient of friction at (a) $0.2 \mathrm{~m} / \mathrm{s}$, (b) $1.8 \mathrm{~m} / \mathrm{s}$, and (c) $3.3 \mathrm{~m} / \mathrm{s}$. (d) Mean coefficient of friction.

in the W-I composition that did not contain WTRPs. The lower peak temperatures registered in the W-II and W-III compositions can be attributed to the presence of WTRPs. WTRPs contain carbon black, which was added during tire manufacturing to improve the wear resistance [3], this allows them to behave as miniature heat sinks that help in reducing the temperature rise at the interface of the brake lining and counter disc [20].

The specific volumetric loss rate for the four compositions at different load levels and speeds is shown in Fig. 10. The specific volumetric loss rate was found to decrease with increasing WTRP weight fraction. W-III with $15 \mathrm{wt} \%$ WTRPs showed the lowest specific volumetric loss rate $\left(1,662 \mu \mathrm{m}^{3} /(\mathrm{N} \cdot \mathrm{m})\right)$ among the fabricated compositions, and it was only marginally larger than the specific volumetric loss rate of the commercial lining W-IV $\left(1,627 \mu \mathrm{m}^{3} /(\mathrm{N} \cdot \mathrm{m})\right)$. However, the density of the commercial lining W-IV was 1.12 times higher than that of W-III. From this, it can be deduced that the inertia of the brake lining would be less for W-III, thus facilitating retraction on release of the brakes. However, W-III would have a shorter lifespan than W-IV for the same brake lining size. Because the speed of sound in hard tire rubber is approximately $300 \mathrm{~m} / \mathrm{s}$ [34], WTRPs offer an additional acoustic advantage by damping the sound caused by the sudden contact of the brake lining with the counter face disc during operation. The WTRP-based linings were quieter during operation than the commercial lining.

Table 6 shows the average coefficient of friction and the specific rate of volumetric loss for the brake linings. The performance of the W-III composition was similar to that of the commercial lining W-IV. Wear morphological studies were conducted to further analyze the wear phenomena on brake linings.

Figure 11 shows the wear micrographs of the different brake lining compositions. Recent studies on brake lining wear [28, 35-39] have categorized the different forms of primary and secondary plateau formation on the wear surface. When abrasion is the dominant wear phenomena, then plastically-deformed and non-deformable types of primary plateaus are formed, whereas sliding wear initiates the release of abrading debris [35]. The primary plateaus obstruct the free movement of wear debris. During the sliding action between the contacting brake lining and disc surfaces, the trapped wear debris can be compacted, leading to the formation of a third-body layer or a friction layer that accumulates at the peripheral zones of the primary plateau. If the wear debris consists of 

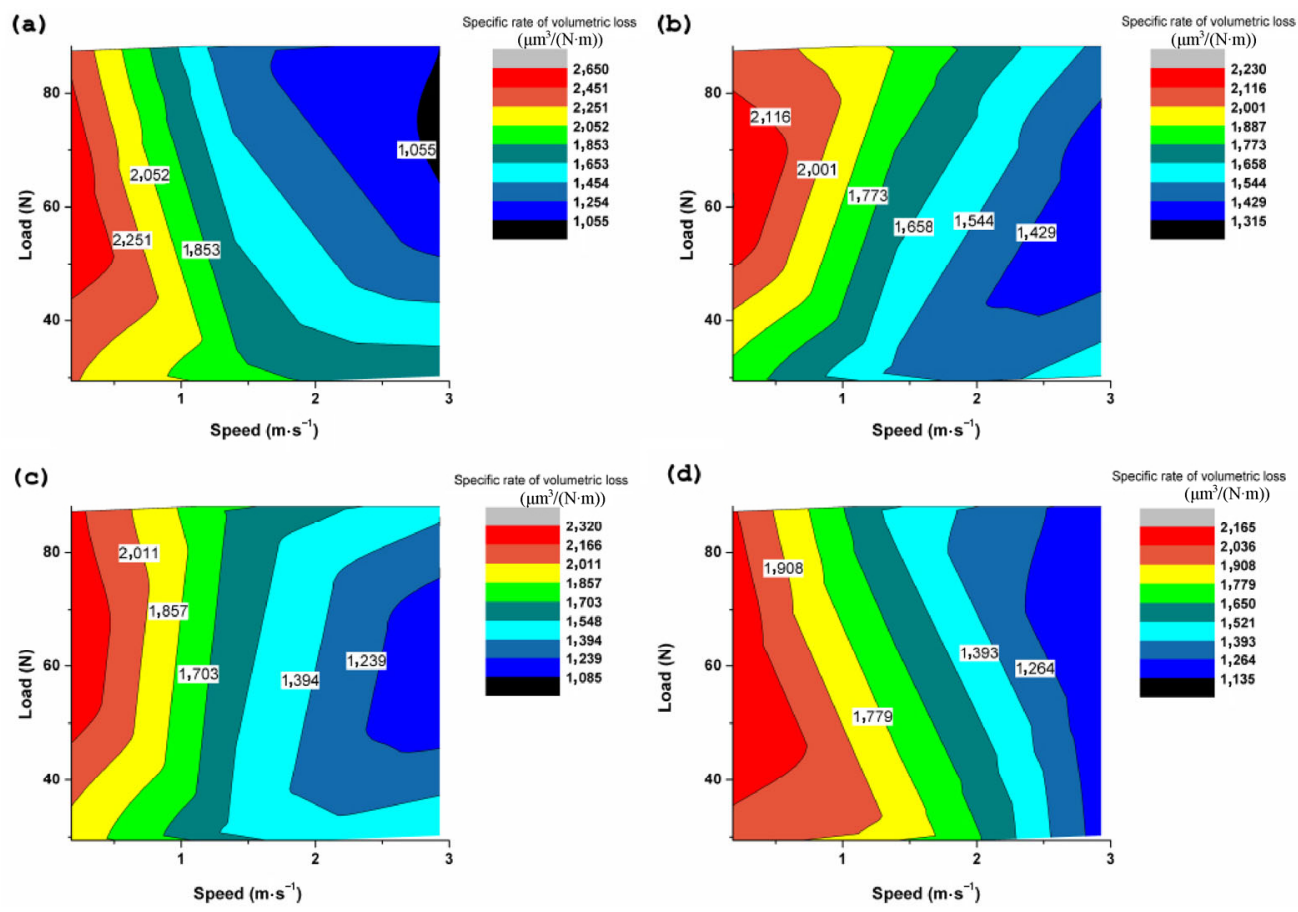

Fig. 10 The specific rate of volumetric loss $\tilde{V}$ for (a) W-I, (b) W-II, (c) W-III, and (d) W-IV.

Table 6 Tribological response of the brake linings.

\begin{tabular}{ccccc}
\hline Parameter & W-I & W-II & W-III & W-IV \\
\hline Mean coefficient of friction $\left(\mu_{\text {mean }}\right)$ & $0.32 \pm 0.02$ & $0.35 \pm 0.02$ & $0.38 \pm 0.02$ & $0.41 \pm 0.03$ \\
Mean specific rate of volumetric loss $\left(\mu \mathrm{m}^{3} /(\mathrm{N} \cdot \mathrm{m})\right)$ & $1,748 \pm 56$ & $1,714 \pm 29$ & $1,662 \pm 39$ & 50 \\
Peak temperature $\left({ }^{\circ} \mathrm{C}\right)$ & 53 & 51 & 39 & 37 \\
Mean temperature $\left({ }^{\circ} \mathrm{C}\right)$ & 40 & 38 & 38 \\
\hline
\end{tabular}
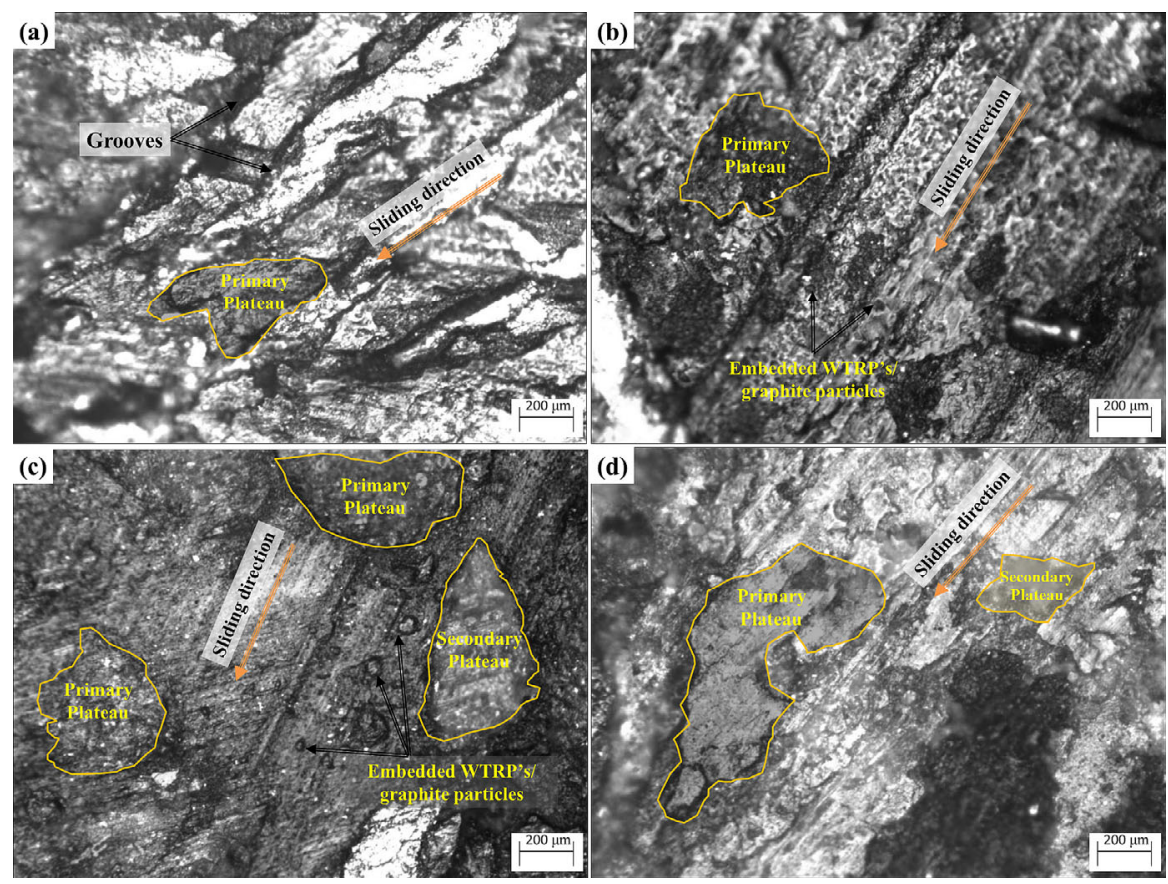

Fig. 11 Wear micrographs to characterize primary and secondary plateau: (a) W-I, (b) W-II, (c) W-III, and (d) W-IV. 
harder particles, then the particles can either indent into the counter faces to form pits or embed onto the softer brake lining surface, where it is pulled along the sliding direction leading to the formation of grooves [36, 37]. The nature of plateaus and wear debris redistribution, which leads to secondary plateau formation, affected the coefficient of friction and wear phenomena.

The wear surface morphology of W-I shows the formation of wear grooves containing separated fibers and loosened filler particles. The wear surface reveals larger cracks and a higher extent of binder breakdown, which is reflected directly in the higher measured wear rate. Pits were observed at distinct locations, which can be attributed to abrasion by larger sized particles that were freed from the surface. In the case of the W-II and W-III compositions, binder breakdown occurred when the plastic deformation exceeded the yield strength of the binder material. The deformation was damped to some extent due to the presence of elastomeric WTRPs. Hence the surfaces of W-II and W-III are more resistant to abrasive wear than W-I. The embedment of wear debris and filler particles was observed at specific pockets on the W-II and W-III compositions. Wear morphology of W-IV showed accelerated formation of a larger plastically-deformed primary plateau zone and small zones of secondary plateau. SEM-EDS spectra, shown in Fig. 12, were captured for the W-III composition, and they show the presence of the following elements: C from WTRPs, graphite and the binder, $\mathrm{O}$ from the laterite filler and binder, $\mathrm{Na}$ from the fiber and binder as $\mathrm{NaOH}$ was used as a catalyst for the phenol-formaldehyde reaction to form a resol resin, and S from WTRPs as sulfur was added during vulcanization [39].

\section{Conclusions}

The effect of WTRPs on brake lining materials and a comparison of WTRP-based brake linings with a commercial-grade one was conducted. Specifically, the mechanical and tribological characteristics, and the wear surface morphology were studied. The following conclusions were drawn:

(1) Higher WTRP content augmented the compressive strength of the brake lining materials while reducing

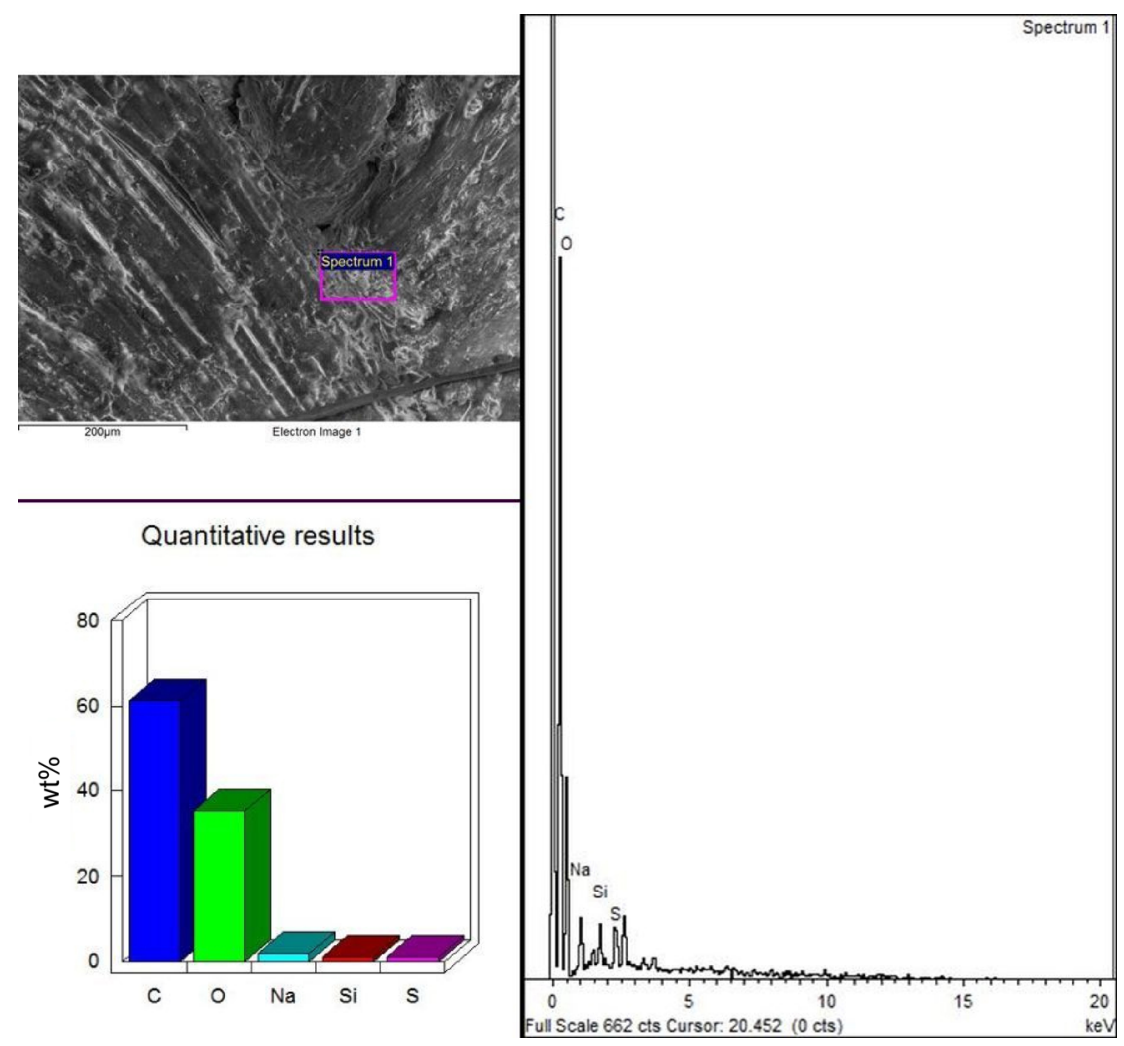

Fig. 12 SEM-EDS spectra of W-III composition. 
their mass density, which aids in reducing the inertia of the brake liners when the brakes are released. However, there was a reduction in the hardness with increasing WTRP content. The W-III composition showed the optimal compressive strength and mass density with hardness that was $\sim 70 \%$ of the commercial lining W-IV. Based on the mechanical response of the brake linings, W-III was determined to be the optimal composition.

(2) WTRPs as fillers in the brake lining materials led to improved coefficients of friction and wear resistance while also adding an acoustic advantage in terms of sound damping and shock cushioning when the brake lining and counter face disc are contacted.

(3) The temperature rise at the brake lining-counter disc interface was reduced as the WTRP weight fraction in the brake linings increased, thus showcasing WTRPs as minuscule heat sinks.

(4) On benchmarking with a commercial-grade heavyduty brake lining, the lining with $15 \mathrm{wt} \%$ WTRPs (W-III) showed an on par tribological performance as W-IV. Due to its lower density, the specific compressive strength of W-III was found to be higher than that of W-IV, which makes the $15 \mathrm{wt} \%$ WTRP brake lining attractive for commercial vehicle applications.

(5) The wear surfaces of W-III showed a primary plateau that was formed by abrasion and debris released due to sliding wear. The released debris were trapped within the worn surface and underwent compaction causing the formation of a third-body or friction layer in the vicinity of the primary plateau.

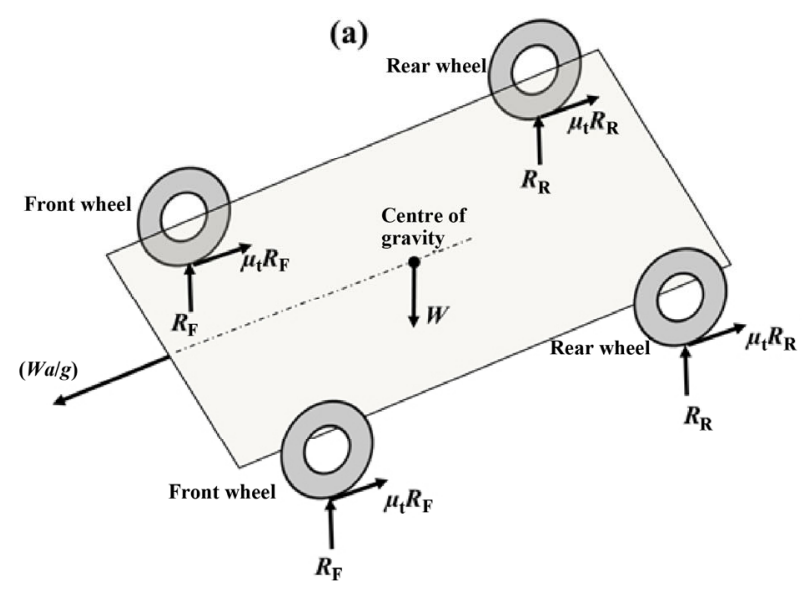

Fig. 13 (a) Braking efforts for a truck and (b) side view of a truck.

\section{Acknowledgements}

The current research work received financial support from the Karnataka State Council for Science and Technology. The authors would like to thank Dr. Satish Shenoy B, professor and head of Department of Aeronautical \& Automobile Engineering and the Department of Mechanical and Manufacturing Engineering, Manipal Institute of Technology for rendering the necessary infrastructural support for the work.

\section{Appendix}

A model of the brake system on commercial vehicles was used to determine operational parameters for the experimental setup. The load distribution, road reaction and the braking effort of the tires for a regular truck are displayed in Fig. 13.

The road reactions at all the wheels can be estimated by static analysis (Eqs. (A1) and (A2)). For a $4 \times 2$ rigid, fully-forward truck configuration with $10 \times 20$ tires, the gross vehicle weight $(W)$ is $16,000 \mathrm{~kg}$. If taken as equidistant from the front and rear axles, the center of gravity relative to the rear axle $(x)$ will be equal to half of the vehicle wheelbase (b) as given by Eq. (A3). At each wheel, the minimum braking force applied by the brake lining on the drum must be equal to the braking effort, as given by Eq. (A4).

$$
\begin{gathered}
R_{\mathrm{F}}=\frac{W}{2}\left(1-\frac{x}{b}\right) \\
R_{\mathrm{R}}=\frac{W x}{2 b}
\end{gathered}
$$

(b)

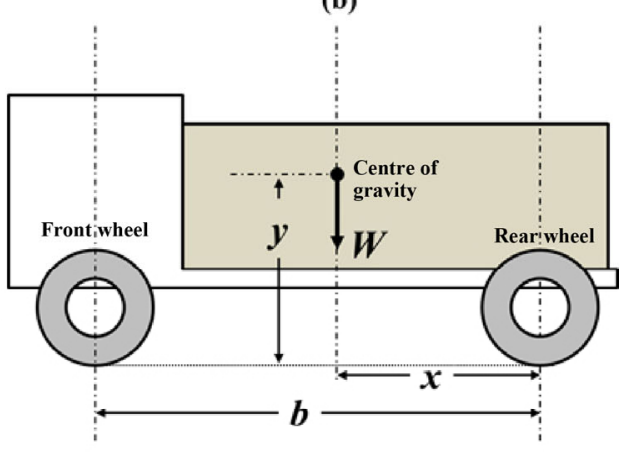




$$
\begin{gathered}
x=\frac{b}{2} \\
\mu_{\mathrm{t}} R_{\mathrm{F}} \geq \mu_{\mathrm{b}} F_{\mathrm{bs}}
\end{gathered}
$$

Open Access: This article is licensed under a Creative Commons Attribution 4.0 International License, which permits use, sharing, adaptation, distribution and reproduction in any medium or format, as long as you give appropriate credit to the original author(s) and the source, provide a link to the Creative Commons licence, and indicate if changes were made.

The images or other third party material in this article are included in the article's Creative Commons licence, unless indicated otherwise in a credit line to the material. If material is not included in the article's Creative Commons licence and your intended use is not permitted by statutory regulation or exceeds the permitted use, you will need to obtain permission directly from the copyright holder.

To view a copy of this licence, visit http://creativecommons.org/licenses/by/4.0/.

\section{References}

[1] Öztürk B, Öztürk S, Adigüzel A A. Effect of type and relative amount of solid lubricants and abrasives on the tribological properties of brake friction materials. Tribol Trans 56(3): 428-441 (2013)

[2] Öztürk B, Arslan F, Öztürk S. Effects of different kinds of fibers on mechanical and tribological properties of brake friction materials. Tribol Trans 56(4): 536-545 (2013)

[3] Kan T, Strezov V, Evans T. Fuel production from pyrolysis of natural and synthetic rubbers. Fuel 191: 403-410 (2017)

[4] Muñoz-Sánchez B, Arévalo-Caballero M J, Pacheco-Menor $\mathrm{M}$ C. Influence of acetic acid and calcium hydroxide treatments of rubber waste on the properties of rubberized mortars. Mater Struct 50: 75 (2017)

[5] Ghosh P, Ghosh D, Khastgir D, Chaki T K. Effect of aramid pulp and lapinas fiber on the friction and wear behavior of NBR powder-modified phenolic resin composite. Tribol Trans 59(3): 391-398 (2016)

[6] Singh T, Patnaik A, Chauhan R. Optimization of tribological properties of cement kiln dust-filled brake pad using grey relation analysis. Mater Des 89: 1335-1342 (2016)

[7] Stephen B S, Jayakumari L S. Effect of rockwool and steel fiber on the friction performance of brake lining materials. Rev Mater 21(3): 656-665 (2016)

[8] Han Y, Tian X F, Yin Y S. Effects of ceramic fiber on the friction performance of automotive brake lining materials. Tribol Trans 51(6): 779-783 (2008)

[9] Sugozu I, Mutlu I, Sugozu K B. The effect of ulexite to the tribological properties of brake lining materials. Polym Compos 39(1): 55-62 (2018)

[10] Sugozu I, Mutlu I, Sugozu K B. The effect of colemanite on the friction performance of automotive brake friction materials. Ind Lubr Tribol 68(1): 92-98 (2016)

[11] Fan Y L, Matějka V, Kratošová G, Lu Y F. Role of $\mathrm{Al}_{2} \mathrm{O}_{3}$ in semi-metallic friction materials and its effects on friction and wear performance. Tribol Trans 51(6): 771-778 (2008)

[12] Ilanko A K, Vijayaraghavan S. Wear behavior of asbestos-free eco-friendly composites for automobile brake materials. Friction 4(2): 144-152 (2016)

[13] Menapace C, Leonardi M, Perricone G, Bortolotti M, Straffelini G, Gialanella S. Pin-on-disc study of brake friction materials with ball-milled nanostructured components. Mater Des 115: 287-298 (2017)

[14] Li X, Tabil L G, Panigrahi S. Chemical treatments of natural fiber for use in natural fiber-reinforced composites: A review. J Polym Environ 15(1): 25-33 (2007)

[15] Mahale V, Bijwe J, Sinha S. Influence of nano-potassium titanate particles on the performance of NAO brake-pads. Wear 376-377: 727-737 (2017)

[16] Khaleghian S, Emami A, Taheri S. A technical survey on tire-road friction estimation. Friction 5(2): 123-146 (2017)

[17] ASTM International. ASTM D2734-94: Standard test methods for void content of reinforced plastics. West Conshohocken (USA): SATM, 2016.

[18] Verma P C, Menapace L, Bonfanti A, Ciudin R, Gialanella S, Straffelini G. Braking pad-disc system: Wear mechanisms and formation of wear fragments. Wear 322-323: 251-258 (2015)

[19] Guo F, Zhang Z Z, Liu W M, Su F H, Zhang H J. Effect of plasma treatment of Kevlar fabric on the tribological behavior of Kevlar fabric/phenolic composites. Tribol Int 42(2): 243-249 (2009)

[20] Verma P C, Ciudin R, Bonfanti A, Aswath P, Straffelini G, Gialanella S. Role of the friction layer in the high-temperature pin-on-disc study of a brake material. Wear 346-347: 56-65 (2016)

[21] Plachá D, Vaculík M, Mikeska M, Dutko O, Peikertová P, Kukutschová J, Mamulová Kutláková K, Růžičková J, Tomášek V, Filip P. Release of volatile organic compounds by oxidative wear of automotive friction materials. Wear 376-377: 705-716 (2017)

[22] Bian G Y, Wu H Z. Friction surface structure of a $\mathrm{C}_{\mathrm{f}} / \mathrm{C}-\mathrm{SiC}$ composite brake disc after bedding testing on a full-scale dynamometer. Tribol Int 99: 85-95 (2016) 
[23] Abdullah O I, Schlattmann J. Temperature analysis of a pin-on-disc tribology test using experimental and numerical approaches. Friction 4(2): 135-143 (2016)

[24] ASTM International. ASTM G99-17: Standard test method for wear testing with a pin-on-disk apparatus. West Conshohocken (USA): ASTM, 2017.

[25] Garrett T K, Newton K, Steeds W. Emission control. In Motor Vehicle. Garrett T K, Newton K, Steeds W, Eds. Oxford: Butterworth-Heinemann, 2000.

[26] Pechurai W, Sahakaro K, Nakason C. Influence of phenolic curative on crosslink density and other related properties of dynamically cured NR/HDPE blends. J Appl Polym Sci 113(2): 1232-1240 (2009)

[27] Luo T, Isayev A I. Rubber/plastic blends based on devulcanized ground tire rubber. J Elastom Plast 30(2): 133-160 (1998)

[28] Barros L Y, Neis P D, Ferreira N F, Pavlak R P, Masotti D, Matozo L T, Sukumaran J, De Baets P, Andó M. Morphological analysis of pad-disc system during braking operations. Wear 352-353: 112-121 (2016)

[29] Elsen S R, Ramesh T. Optimization to develop multiple response hardness and compressive strength of zirconia reinforced alumina by using RSM and GRA. Int J Refract Met Hard Mater 52: 159-164 (2015)

[30] Ahmed A R, Irhayyim S S, Hammood H S. Effect of yttrium oxide particles on the mechanical properties of polymer matrix composite. IOP Conf Ser: Mater Sci Eng 454: 012036 (2018)

[31] Srivastava V K, Verma A. Mechanical behaviour of copper and aluminium particles reinforced epoxy resin composites. Am J Mater Sci 5(4): 84-89 (2015)

[32] Khairnar H P, Phalle V M, Mantha S S. Estimation of automotive brake drum-shoe interface friction coefficient under varying conditions of longitudinal forces using Simulink. Friction 3(3): 214-227 (2015)

[33] Aranganathan N, Bijwe J. Development of copper-free

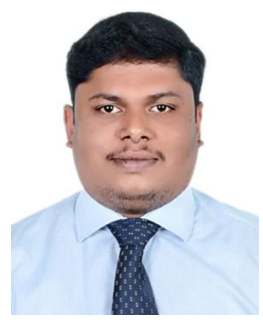

Anand PAI. He received his bachelor degree in mechanical engineering in 2005 from National Institute of Technology Karnataka, Surathkal, India. Then, he served in the Commercial Vehicle Industry for nearly 7 years. Later, he obtained his M.Tech. degree in manufacturing engineering eco-friendly brake-friction material using novel ingredients. Wear 352-353: 79-91 (2016)

[34] Heißing B, Ersoy M. Chassis Handbook: Fundamentals, Driving Dynamics, Components, Mechatronics, Perspectives. Wiesbaden (Germany): Vieweg Verlag, 2011.

[35] Neis P D, Ferreira N F, Fekete G, Matozo L T, Masotti D. Towards a better understanding of the structures existing on the surface of brake pads. Tribol Int 105: 135-147 (2017)

[36] Laguna-Camacho J R, Juárez-Morales G, Calderón-Ramón C, Velázquez-Martínez V, Hernández-Romero I, MéndezMéndez J V, Vite-Torres M. A study of the wear mechanisms of disk and shoe brake pads. Eng Fail Anal 56: 348-359 (2015)

[37] Lazim A R M, Kchaou M, Hamid M K A, Bakar A R A. Squealing characteristics of worn brake pads due to silica sand embedment into their friction layers. Wear 358-359: 123-136 (2016)

[38] Pai A, Sharma S S, D'Silva R E, Nikhil R G. Effect of graphite and granite dust particulates as micro-fillers on tribological performance of Al 6061-T6 hybrid composites. Tribol Int 92: 462-471 (2015)

[39] Pai A, Kini M V, Pokharel V. Influence of a novel hardener $p$-toluene sulfonic acid on mechanical and wear response of phenolic-based friction materials. Tribology Transactions 60(5): 770-780 (2016)

[40] ASTM International. ASTM D695-15: Standard test method for compressive properties of rigid plastics. West Conshohocken (USA): ASTM, 2008.

[41] ASTM International. ASTM D792-13: Standard test methods for density and specific gravity (relative density) of plastics by displacement. West Conshohocken (USA): ASTM, 2008.

[42] ASTM International. ASTM E384-16: Standard test method for microindentation hardness of materials. West Conshohocken (USA): ASTM, 2016.

and technology in 2015 from Manipal Institute of Technology (MIT), Manipal, India. He joined the Department of Aeronautical and Automobile Engineering, MIT Manipal as a faculty and is currently pursuing his Ph.D. degree at the same university. His research interests include automotive systems and technology, composite materials, and tribology in automobiles. 